\title{
Effect of the Alloying Metal on the Corrosion Resistance of Pd-Rich Binary Alloys with Pt, Rh, and Ru in Sulfuric Acid
}

\author{
Katarzyna Hubkowska ${ }^{1, *}$, Julian Kubisztal ${ }^{2}$ (), Małgorzata Pająk ${ }^{1}$, Bożena Losiewicz ${ }^{2}$ (1) \\ and Andrzej Czerwiński ${ }^{1}$ \\ 1 Faculty of Chemistry, University of Warsaw, Pasteura 1, 02-093 Warsaw, Poland; \\ mpajak@chem.uw.edu.pl (M.P.); aczerw@chem.uw.edu.pl (A.C.) \\ 2 Institute of Materials Engineering, Faculty of Science and Technology, University of Silesia in Katowice, \\ 75 Pulku Piechoty 1A, 41-500 Chorzow, Poland; julian.kubisztal@us.edu.pl (J.K.); \\ bozena.losiewicz@us.edu.pl (B.Ł.) \\ * Correspondence: khubkowska@chem.uw.edu.pl
}

Citation: Hubkowska, K.; Kubisztal, J.; Pająk, M.; Łosiewicz, B.;

Czerwiński, A. Effect of the Alloying Metal on the Corrosion Resistance of Pd-Rich Binary Alloys with Pt, Rh, and Ru in Sulfuric Acid. Materials 2021, 14, 2923. https://doi.org/ $10.3390 /$ ma14112923

Academic Editor: Guang-Ling Song

Received: 30 March 2021

Accepted: 25 May 2021

Published: 28 May 2021

Publisher's Note: MDPI stays neutral with regard to jurisdictional claims in published maps and institutional affiliations.

Copyright: (c) 2021 by the authors. Licensee MDPI, Basel, Switzerland. This article is an open access article distributed under the terms and conditions of the Creative Commons Attribution (CC BY) license (https:// creativecommons.org/licenses/by/ $4.0 /)$.

\begin{abstract}
The paper presents the study of the corrosion resistance of electrodeposited Pd and its binary alloys with $\mathrm{Pt}, \mathrm{Rh}$, and $\mathrm{Ru}$ on a polycrystalline Au substrate. The corrosion resistance was tested in $0.5 \mathrm{M}$ sulfuric acid at room temperature using potentiodynamic polarization and electrochemical impedance spectroscopy techniques. The morphology/composition and work function values were determined by scanning electron microscopy/energy-dispersive $\mathrm{X}$-ray spectroscopy and scanning Kelvin probe, respectively. The obtained results revealed that the Pd electrode is the most resistant to corrosion, whereas the Pd-Ru electrode is the most susceptible to dissolution. It was found that the corrosion resistance of Pd-binary alloys decrease in the following order: $\mathrm{Pd}>\mathrm{Pd}-\mathrm{Pt}>\mathrm{Pd}-\mathrm{Rh}>\mathrm{Pd}-\mathrm{Ru}$. This effect was assigned mainly to the difference in surface roughness factor of tested electrodes.
\end{abstract}

Keywords: Pd; Pd-Rh alloy; Pd-Ru alloy; Pd-Pt alloy; electrodeposition; corrosion resistance; SKP; work function; fermi level

\section{Introduction}

In recent times, palladium and its alloys with other noble metals have been intensively studied as they can improve the chemical and mechanical properties of metal coatings. It is especially important for industrial applications, where protective coatings are applied to enhance the corrosion resistance of bare metal. Pd/Ag alloys are used in dentistry as they are biocompatible and have high distortion resistance during porcelain firing [1]. They are also used as membranes for hydrogen separation and hydrogen storage materials [2,3]. Palladium alloyed with $\mathrm{Ni}, \mathrm{Co}$, or $\mathrm{Cu}$ is used to obtain cathodic coatings on stainless steel as the noble metal enhances passivation and improves the corrosion resistance [4-6]. $\mathrm{Pd} / \mathrm{Ni}$ alloys are mostly used for electrically conductive surfaces as they have an excellent wear resistance [7]. $\mathrm{Au} / \mathrm{Pd}$ surface finish is also utilized in electronic industry to enhance solderability and oxidation resistance [8]. Pd-based binary and ternary alloys have recently been screened in electrocatalytic reduction of $\mathrm{CO}_{2}$ and $\mathrm{O}_{2}$ or formaldehyde and $\mathrm{CO}$ oxidation since they are comparatively inexpensive, have higher catalytic activity and lower sensitivity to poisoning effect in comparison with a platinum catalyst [9-14].

In the last decades, palladium and its alloys with $\mathrm{Pt}, \mathrm{Ru}$, and $\mathrm{Rh}$ have also been extensively studied in an aspect of hydrogen absorption phenomenon from both aqueous and non-aqueous electrolytes, as well as from the gas phase [15-26]. The addition of a second noble metal to palladium changes the properties of the alloy for hydrogen absorption. It is caused by alteration of the structure of crystal lattice, elastic and electronic properties. Consequently, it results in changes in the kinetics of the sorption process, the amount of the absorbed hydrogen, and the range of absorption/desorption hysteresis [21,27-29]. Pd and $\mathrm{Pt}$ form a solid solution, and its lattice parameters somewhat increase with $\mathrm{Pt}$ addition 
(expanded alloys) [30]. In the case of Pd-Ru and Pd-Rh alloys after the addition of alloying metal the decrease of lattice constant is observed and therefore, they are classified as contracted alloys [21,31]. Pd-rich Pd-Pt alloys absorb hydrogen electrochemically, similarly to pure Pd. At high Pd bulk content, hydrogen is absorbed in the $\beta$ phase, while at a lower Pd content, the hydrogen is absorbed in the $\alpha$ phase. The ability of the Pd-Pt alloys to absorb hydrogen decreases with increasing Pt bulk content [32]. It is caused by the effect of the valence band broadening upon alloying [30]. On the contrary, in Pd-Ru alloys, in a certain composition range, the increased absorption capacities are observed [20,29]. It is due to the fact that Ru possesses free states around the Pd Fermi level. The amount of absorbed hydrogen increases with the increasing Ru bulk content, and alloys containing 98-99.5 at.\% of Pd absorb more hydrogen than pure Pd [20]. Among various Pd alloys, the best absorption properties show Pd-Rh systems, and the highest amount of the absorbed hydrogen is observed for alloys containing $\leq 20$ at. $\%$ of Rh. Doping the palladium with rhodium increases the amount of $4 \mathrm{~d}$ band vacancies, facilitating the transfer of hydrogen to this band, and the solubility of hydrogen in the $\beta$ hydride phase is larger than in $\operatorname{Pd~[16].~}$

The well-known and uncomplicated method for the production of numerous alloys is electrodeposition. The morphology, composition, microstructure, physicochemical properties, and thickness of the electrodeposits can be controlled by the deposition techniques and their parameters, i.e., current, voltage, temperature, or bath composition [33]. Since in $\mathrm{Pd}-\mathrm{Ru}$ and Pd-Rh systems large miscibility gap is observed, it should be taken into account when selecting the method of preparation of the alloys [34,35].

Despite extensive studies on Pd-noble metals alloys' ability to hydrogen absorption, there is a lack of information about the corrosion resistance of such alloys. Hence, this study aims to investigate the corrosion behavior of three Pd-noble metal electrodeposited alloys, i.e., Pd-Ru, Pd-Rh, and Pd-Pt. Since previously conducted research on the hydrogen electrosorption in Pd-based alloys were carried out in $0.5 \mathrm{M}$ sulfuric acid, this medium has been chosen in corrosion experiments. The DC method of potentiodynamic polarization and the AC method of electrochemical impedance spectroscopy (EIS) were used. The obtained results were compared with those for the pure Pd electrodeposit.

\section{Materials and Methods}

\subsection{Material Preparation}

The Pd-noble metal alloys were prepared by potentiostatic electrodeposition on a polycrystalline gold plate $(0.12 \mathrm{~mm}$ thick, $99.99 \%$, Mint-Metals, Radzymin, Poland) from baths containing water solutions of $0.11 \mathrm{M} \mathrm{PdCl}_{2}$ acidified with $1 \mathrm{M} \mathrm{HCl}$ and $0.05 \mathrm{M}$ $\mathrm{H}_{2} \mathrm{PtCl}_{6}, 0.32 \mathrm{M} \mathrm{RuCl}_{3}$, or $0.5 \mathrm{M} \mathrm{RhCl}_{3}$, separately, depending on the desired alloy. The thickness of electrodeposits was ca. $1 \mu \mathrm{m}$. It was confirmed by the calculations based on the deposition charge and deposition efficiency designated previously [19,21,31]. All solutions were prepared from analytical grade reagents and ultra-pure water (Millipore, Burlington, MA, USA). Detailed physicochemical characteristics of electrodeposited Pd-based electrodes can be found in [36]. The formation of the alloys was confirmed previously [31,36] by XRD analysis and simultaneously for hydrogen-absorbing alloys by the change of the $\alpha \rightarrow \beta$ phase transition potential compared to pure $\operatorname{Pd}[19,21,31]$.

\subsection{Electrochemical Measurements}

The electrochemical measurements were conducted in $0.5 \mathrm{M} \mathrm{H}_{2} \mathrm{SO}_{4}$ deaerated with argon (99.999\%, Air Products, Warsaw, Poland) for 30 min. During experiments, an argon stream was directed over the solution. A three-electrode system was used with a thin layer alloy as a working electrode, $\mathrm{Hg}\left|\mathrm{Hg}_{2} \mathrm{SO}_{4}\right| 0.5 \mathrm{M} \mathrm{H}_{2} \mathrm{SO}_{4}$ as a reference electrode, and $\mathrm{Pt}$ gauze as an auxiliary electrode. All electrochemical measurements were performed by means of CH Instruments Electrochemical Workstation (CHI 760d, Inc., Austin, TX, USA). The potentials were recalculated in reference to the reversible hydrogen electrode (RHE).

EIS measurements were performed at open circuit potential $(O C P)$ using $\mathrm{AC}$ amplitude of $10 \mathrm{mV}$, and frequencies range from $10 \mathrm{kHz}$ to $5 \mathrm{mHz}$ (10 frequencies per decade). EIS 
spectra were analyzed by the complex non-linear least squares (CNLS) method using ZSimpWin 3.21 software (EChem, Ann Arbor, MI, USA). Potentiodynamic polarization curves were registered at a potential range of $\pm 200 \mathrm{mV}$ against OCP. The analysis of the experimental EIS data was carried out using the selected equivalent electrical circuits.

\subsection{Material Characteristics Methods}

The bulk composition of the Pd-based alloys was determined by energy-dispersive $\mathrm{X}$ ray spectroscopy (EDX, Quantax 400 energy dispersive X-ray spectroscope, Bruker, Billerica, MA, USA). The surface morphology observations were performed using scanning electron microscopy (SEM, Merlin field emission scanning electron microscope, Zeiss, Germany). The contact potential difference $(C P D)$ maps of electrodeposits were recorded by scanning Kelvin probe (SKP) using PAR Model 370 Scanning Electrochemical Workstation (Princeton Applied Research, Oak Ridge, TN, USA) equipped with a tungsten SKP microprobe (Ø $500 \mu \mathrm{m}$, Princeton Applied Research, Oak Ridge, TN, USA).

\section{Results and Discussion}

\subsection{Morphology and Bulk Composition of the Pd-Alloys before and after Corrosion}

The electrodeposition of the Pd-rich (below 5 at.\% of alloying metal: see Table 1) Pdbinary alloys with $\mathrm{Rh}, \mathrm{Ru}$, and $\mathrm{Pt}$ leads to obtaining grey and smooth layers. As-deposited $\mathrm{Pd}$ and Pd-based alloys are uniform and free of cracks (Figure 1a,c,e,g). The electrodeposits' surface morphology generally resembles the one for the pure Pd, where star-like crystallites are present. The surface morphology of Pd-Rh alloy is similar to pure Pd; however, it is more lamellar. In the case of Pd-Ru alloys, lamellas and finer round crystallites are visible at the surface. The surface morphology of the Pd-Pt alloy is also lamellar but with crystallites similar in size, bigger than in the case of Pd and other studied alloys.

Table 1. Chemical compositions (EDX) of Pd-binary alloys before and after corrosion in at.\%.

\begin{tabular}{|c|c|c|}
\hline Alloy Type & As-Deposited & After Corrosion \\
\hline Pd-Rh & $96.9(4) \% \operatorname{Pd} 3.1(4) \% \mathrm{Rh}$ & $97.0(1) \% \operatorname{Pd} 3.0(1) \% \mathrm{Rh}$ \\
\hline Pd-Ru & $96.3(3) \% \operatorname{Pd} 3.7(3) \% \mathrm{Ru}$ & $96.4(3) \% \operatorname{Pd} 3.6(3) \% \mathrm{Ru}$ \\
\hline $\mathrm{Pd}-\mathrm{Pt}$ & $96.7(7) \% \mathrm{Pd} 3.3(7) \% \mathrm{Pt}$ & $94.7(3) \% \mathrm{Pd} 5.3(3) \% \mathrm{Pt}$ \\
\hline
\end{tabular}

After applying the corrosion experiment using the potentiodynamic technique, the morphology of the Pd and its alloys have been changed. Many cracks are visible at the surface of all studied samples (Figure $1 \mathrm{~b}, \mathrm{~d}, \mathrm{f}, \mathrm{h}$ ). Moreover, the corrosion process results in a degradation of lamellas in the areas between the cracks. Small particles form more amorphous structures, whereas larger lamellar-shaped particles tend to break into parts or merge into larger lips-like structures. However, the Pd-Ru alloy seems to be an exception to above discussion since after the corrosion (Figure 1f), only amorphous morphology is visible. It is mostly due to the fact that the particles at the surface of as-deposited Pd-Ru alloys are the smallest among all examined alloys.

For the Pd-Rh alloys in the areas between the cracks, more amorphous structures are present, indicating a higher rate of corrosion. The morphology of Pd-Ru alloys after corrosion differs from the morphology of other electrodes. In the case of $\mathrm{Pd}-\mathrm{Ru}$, the cracks of various sizes are visible: larger cracks than for other electrodes and more minor cracks inside the areas limited by larger ones. Moreover, the crystallites' size significantly diminishes, indicating that all surface has been involved in the dissolution process.

EDX measurements revealed that Pd binary alloys with similar content of the different alloying metal (Table 1) can be obtained by the tuning the electrodeposition potential and ions concentrations in galvanic baths. After the corrosion experiment, the bulk composition of the alloys was determined again. One can note that no changes in the bulk composition occurred for the Pd-Rh and Pd-Ru alloys. However, for the Pd-Pt alloys, slight enrichment (ca. 2 at.\%) in Pt is observed. 


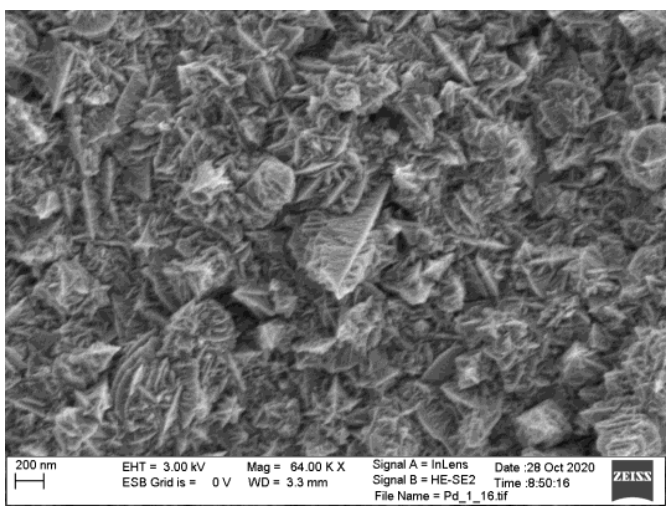

(a)

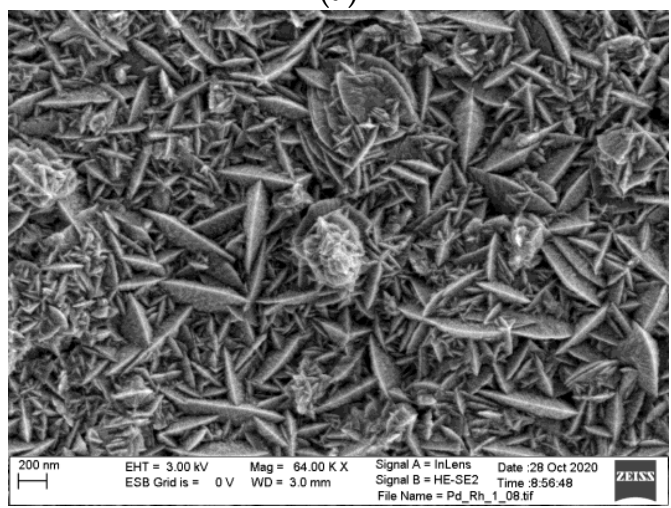

(c)

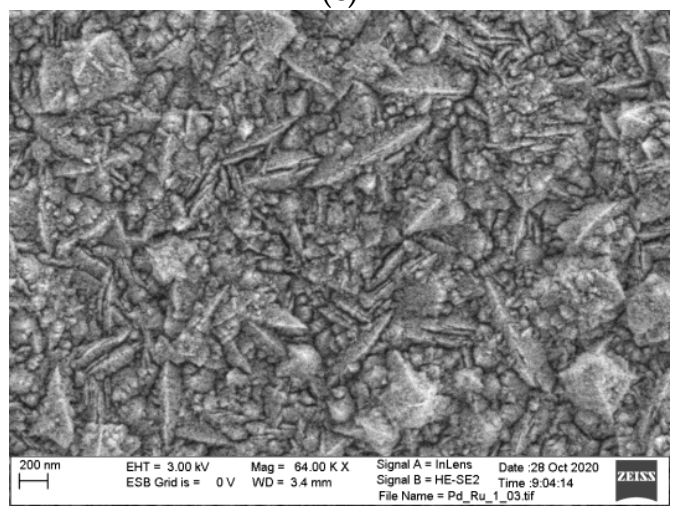

(e)

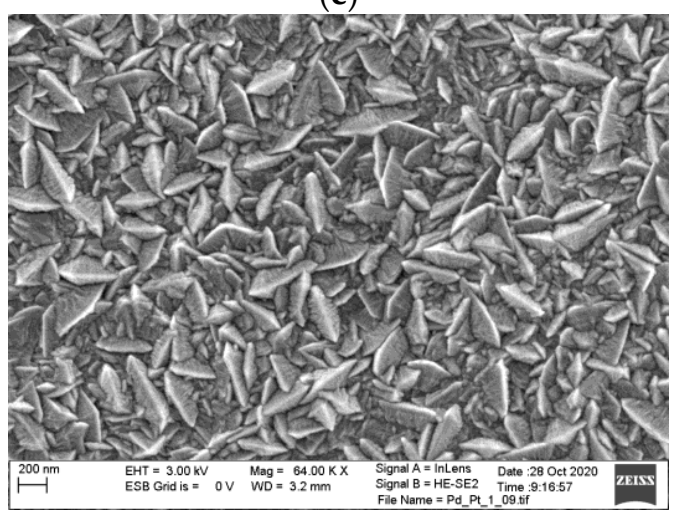

(g)

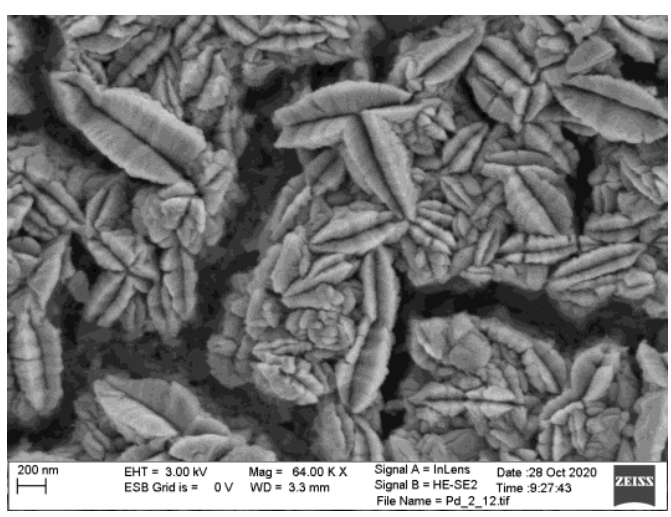

(b)

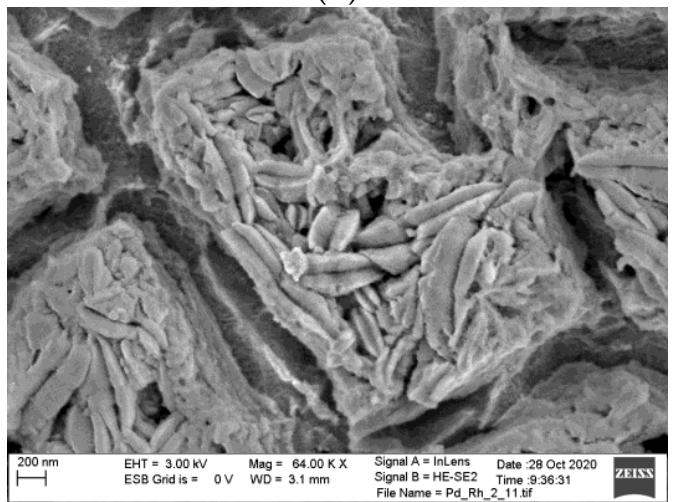

(d)

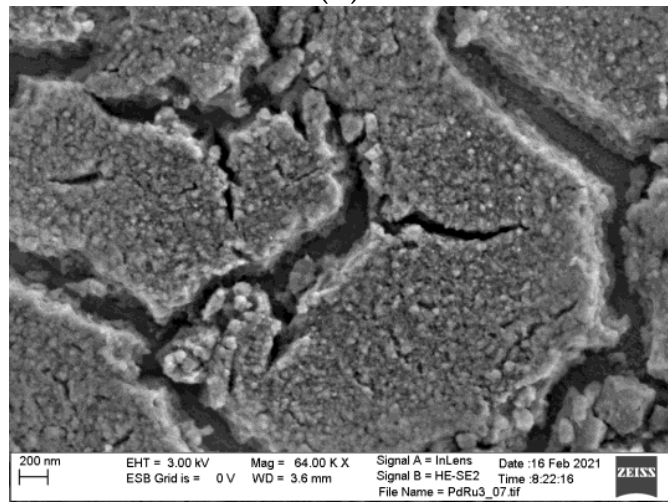

(f)

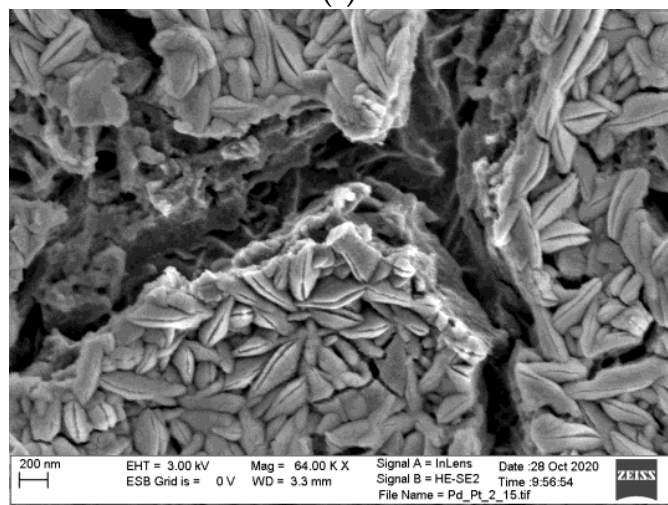

(h)

Figure 1. Surface morphology of the electrodeposited Pd and Pd-based alloys: (a) As-deposited Pd; (c) As-deposited Pd-Rh; (e) As-deposited Pd-Ru; (g) As-deposited Pd-Pt; (b) Pd after corrosion; (d) Pd-Rh after corrosion; (f) Pd-Ru after corrosion; (h) Pd-Pt after corrosion. 
Pd-Pt, Pd-Rh [37], and Pd-Ru [38] alloys have been previously tested in relation to their resistance to electrochemical dissolution. The alloy electrodes with different compositions were cycled to various upper limits of potentials $(0.3 \div 1.5 \mathrm{~V}$ vs. RHE) with a scanning rate of $100 \mathrm{mV} \mathrm{s}^{-1}$. Cyclic voltammetry measurements were coupled with electrochemical quartz crystal microbalance (EQCM). In the case of every tested type of alloy, it was found that alloying $\mathrm{Pd}$ with $\mathrm{Rh}, \mathrm{Ru}$, and Pt results in the increase of the resistance to electrochemical dissolution in described experimental conditions. It was reported by the decrease of the $\Delta m / S$, which described the change of the electrode mass (determined from EQCM) divided by the real surface area. The use of EQCM also enabled the calculation of the oxidation state $(z)$ of dissolving metals. For Pd and Pd-Pt alloys $z$ value of 2 was obtained, indicating $\mathrm{Pd}$ dissolution to $\mathrm{Pd}^{2+}$ in both cases. This is in line with the composition of $\mathrm{Pd}-\mathrm{Pt}$ alloy obtained after corrosion, where enrichment with $\mathrm{Pt}$ is observed. In the case of Pd-Rh, the value of $z$ was calculated in the range of 2.7-3.3. Here, it was concluded that the $z$ value around 3 for Pd-Rh alloy results from both $\mathrm{Pd}(z=2)$ and $\mathrm{Rh}(z \geq 3)$ dissolution. Long cycling of Pd-Rh electrode to the $1.5 \mathrm{~V}$ resulted in the electrode enrichment in Pd [37]. For Pd-Ru alloy, the calculated value of $z$ equals ca. 2.6, confirming Ru ions' dominant contribution in the process of Pd-Ru alloy dissolution [38]. It is worth noting that below $1 \mathrm{~V}$, mainly $\mathrm{Rh}$ [39] and $\mathrm{Ru}$ [38], are the most soluble, while $\mathrm{Pd}$ dissolution occurs above ca. $1 \mathrm{~V}$. To the above discussion and chemical composition after corrosion, it can be concluded that in the conditions of the potentiodynamic experiment, the amount of the dissolved $\mathrm{Pd}, \mathrm{Rh}$, and $\mathrm{Ru}$ in $\mathrm{Pd}-\mathrm{Rh}$ and $\mathrm{Pd}-\mathrm{Ru}$ alloys are comparable, in general resulting in the same composition than before the corrosion process.

\subsection{Potentiodynamic Measurements}

The results calculated from the potentiodynamic polarization curves shown in Figure 2 are placed in Table 2. The obtained values of the corrosion current $\left(j_{c o r}\right)$ and corrosion potential $\left(E_{c o r}\right)$ indicate that pure $\mathrm{Pd}$ is the most resistant to corrosion. The Pd-Ru and the Pd-Rh alloys occurred to be the most susceptible to corrosion in an acidic medium. Pd-Pt alloy exhibits intermediate behavior between Pd and other alloys. For all the tested samples of Pd-binary alloys, the $b_{\mathrm{a}}$ Tafel slopes' values are higher than $b_{\mathrm{c}}$ Tafel slopes indicate that the anode processes at the $E_{c o r}$ are faster than the cathode processes.

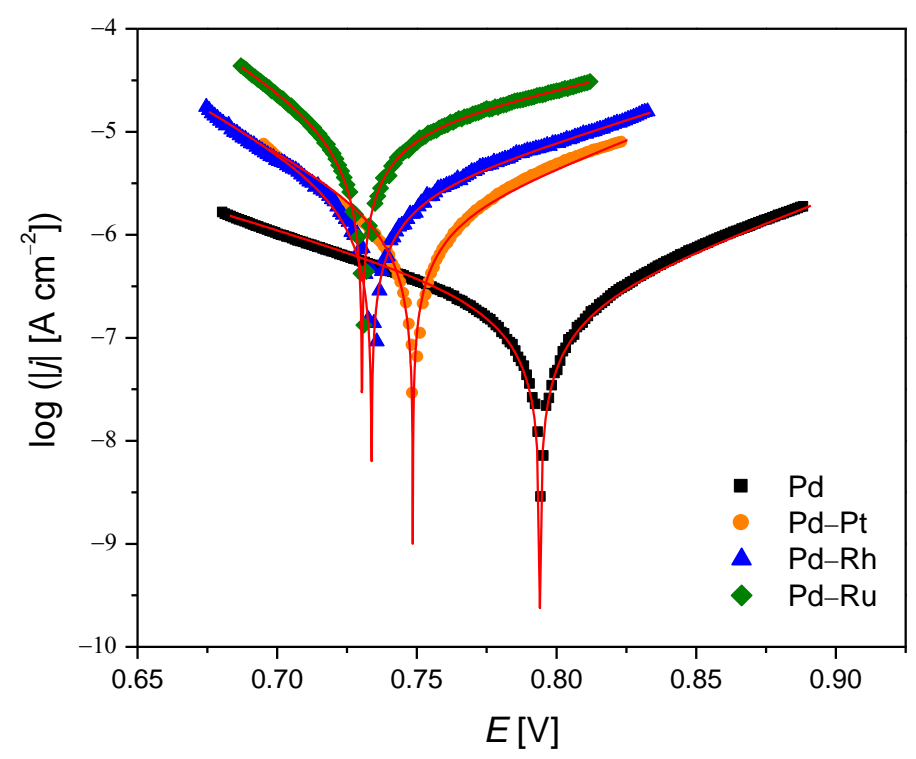

Figure 2. Potentiodynamic polarization curves obtained for electrodeposited $\mathrm{Pd}, \mathrm{Pd}-\mathrm{Rh}, \mathrm{Pd}-\mathrm{Ru}$, and Pd-Pt electrodes in deaerated $0.5 \mathrm{M} \mathrm{H}_{2} \mathrm{SO}_{4}$. Symbols and continuous lines represent experimental data and fits obtained using the Butler-Volmer equation, respectively. 
Table 2. The corrosion resistance parameters for electrodeposited Pd and Pd-binary alloys in deaerated $0.5 \mathrm{M} \mathrm{H}_{2} \mathrm{SO}_{4}$ (see Figure 2).

\begin{tabular}{|c|c|c|c|c|c|c|}
\hline $\begin{array}{l}\text { Alloy } \\
\text { Type }\end{array}$ & $\begin{array}{c}j_{\text {cor }} \\
{\left[\mu \mathrm{A} \mathrm{cm}^{-2}\right]}\end{array}$ & $\begin{array}{c}E_{\text {cor }} \\
{[\mathrm{mV}]}\end{array}$ & $\begin{array}{c}b_{\mathrm{a}} \\
{\left[\mathrm{V} \mathrm{\textrm {dec } ^ { - 1 }}\right]}\end{array}$ & $\begin{array}{c}b_{\mathrm{c}} \\
{\left[\mathrm{V} \mathrm{\textrm {dec } ^ { - 1 }}\right]}\end{array}$ & $\begin{array}{r}R_{\mathrm{p}} \times 10^{4} \\
{\left[\Omega \mathrm{cm}^{2}\right]}\end{array}$ & $\begin{array}{l}C R \text { at } E_{\text {cor }} \\
{\left[\mathrm{mm} \mathrm{yr}^{-1}\right]}\end{array}$ \\
\hline $\mathrm{Pd}$ & $0.26(1)$ & 794.5(3) & $0.096(1)$ & $0.122(1)$ & $9.0(3)$ & $3.8(1) \times 10^{-3}$ \\
\hline Pd-Rh & $2.87(5)$ & $733.6(3)$ & $0.116(2)$ & $0.066(1)$ & $0.63(1)$ & $4.08(7) \times 10^{-2}$ \\
\hline Pd-Ru & 10.1(1) & $730.5(1)$ & $0.159(2)$ & $0.062(1)$ & $0.19(1)$ & $1.43(1) \times 10^{-1}$ \\
\hline $\mathrm{Pd}-\mathrm{Pt}$ & $1.35(4)$ & $748.5(4)$ & $0.093(2)$ & $0.068(2)$ & $1.26(5)$ & $1.92(6) \times 10^{-2}$ \\
\hline
\end{tabular}

The pure Pd electrode exhibits the opposite behavior. The average value of polarization resistance $\left(R_{\mathrm{p}}\right)$ is the highest for the Pd electrode and the lowest for the Pd-Ru alloy electrode. $R_{\mathrm{p}}$ value for the Pd electrode is ca. 47 times higher than for Pd-Ru alloy electrode. These values also confirm the highest corrosion resistance of Pd electrode and the lowest corrosion resistance of the $\mathrm{Pd}-\mathrm{Ru}$ alloy. Since the values of corrosion rate $(C R)$ are inversely proportional to $R_{\mathrm{p}}$ values, the highest value of $C R$ was calculated for Pd-Ru alloy. The lowest value of $C R$ is observed for the Pd electrode. Based on the obtained results, it can be concluded that $\mathrm{Pd}$-based electrodes are resistant to corrosion as follows: $\mathrm{Pd}>\mathrm{Pd}-\mathrm{Pt}>$ Pd-Rh > Pd-Ru.

The corrosion resistance properties of the electrode are dependent on the surface state of the alloys. They are influenced not only by the type of the alloying metals but also by, e.g., oxidation states of the elements and surface roughness factor $(f)$. Table 3 shows the calculated $f$ values of the electrodeposited electrodes. The $f$ values were calculated based on charge originating from the surface oxides reduction, according to the following formula [40]:

$$
f=\frac{Q_{r e d}^{O}}{\theta_{O} Q_{r e d, M L, S}^{O} S}
$$

where $\theta_{O}$ is the surface coverage with surface oxide, $Q^{O} r e d, M L, S$ is the charge from the reduction of a monolayer of surface oxide per unit area, and $S$ is the geometric surface area. Since the experiments have been done on Pd-rich alloys, the charge due to the reduction of a monolayer of surface oxide per unit area equals the same value as in the case of pure $\mathrm{Pd}$, i.e., ca. $424 \mu \mathrm{C} \mathrm{cm}^{-2}$. In the condition of the experiment (polarization to $1.5 \mathrm{~V}$ vs. SHE, scan rate $0.1 \mathrm{Vs}^{-1}$ ) it can be assumed that the oxide monolayer is formed ( $\theta_{O}$ equals to 1 ).

Table 3. Surface roughness factor of the Pd and Pd-binary alloys before $\left(f_{\text {as-deposited }}\right)$ and after corrosion $\left(f_{\text {after corrosion }}\right)$.

\begin{tabular}{ccc}
\hline Alloy Type & $f_{\text {as-deposited }}$ & $f_{\text {after corrosion }}$ \\
\hline $\mathrm{Pd}$ & $1.7(1)$ & $1.3(1)$ \\
$\mathrm{Pd}-\mathrm{Rh}$ & $8.9(7)$ & $15(1)$ \\
$\mathrm{Pd}-\mathrm{Ru}$ & $64(3)$ & $58(3)$ \\
$\mathrm{Pd}-\mathrm{Pt}$ & $1.4(1)$ & $10.4(8)$ \\
\hline
\end{tabular}

One can notice that Pd-Ru alloys exhibit the roughest surface, whereas the Pd electrode surface is the least rough. The $f$ for electrodeposited Pd-based electrodes increase in the following order: $\mathrm{Pd}-\mathrm{Pt}<\mathrm{Pd}<\mathrm{Pd}-\mathrm{Rh}<\mathrm{Pd}-\mathrm{Ru}$. Moreover, $\mathrm{Pd}$ and $\mathrm{Pd}-\mathrm{Pt}$ alloys are characterized by similar $f$ values, indicating the similarity of the real surface area to the geometric one. However, for Pd-Ru alloy, the $f$ value is ca. 37 times higher than for the $\mathrm{Pd}$ electrode. There is no clear correlation between $f$ value before and after corrosion test. The roughness factor significantly increases for Pd-Rh and Pd-Pt electrodes, whereas a slight decrease of the $f$ value is observed for Pd and Pd-Ru electrodes. The increase of the surface roughness factor after the corrosion test can be due to the creation of the large cracks (Figure 1). The presence of the large cracks leads to the exposure of the crystallites from the inner layers, which can contribute to the electrochemical processes. It can be 
seen that the electrochemical corrosion resistance parameters strongly correlate with the $f$ values, i.e., the electrodes with the largest real surface are the least resistant to corrosion. This effect is rather predictable because the size of the surface area of the sample with the highest $f$ value that interact with the electrolyte is much larger than that of the sample with the real surface area close to the geometric one.

\subsection{Scanning Kelvin Probe Measurements}

The measurements with the SKP technique have been done as a complementary method to the potentiodynamic measures. It allows the determination of $C P D$, which can be easily recalculated into the value of work function (WF). The WF definition concerns the difference between the Fermi level and the vacuum level [41]. The values of WF for the same material can be modified through: (i) carrier-doping, which results in the shifting of the Fermi level $\left(E_{F}\right)$ into higher values, and (ii) the modification of the surface dipole, which can increase the WF [41]. WF maps obtained for electrodeposited Pd, Pd-Rh, Pd-Ru and $\mathrm{Pd}-\mathrm{Pt}$ electrodes are presented in Figure $3 \mathrm{a}-\mathrm{d}$ and the corresponding histograms are shown in Figure 4a-d. Skewness and kurtosis are parameters that quantitatively describe peaks/valleys profile and provide information regarding the deviation of the work function distribution from a Gaussian distribution. It was found that skewness and kurtosis are in the range \pm 0.05 for all the investigated materials. Thus, the WF distributions follow a Gaussian distribution. Skewness and kurtosis close to zero indicate also that the WF values are symmetrically distributed around the average value and that there are no inordinately high peaks/deep valleys on the surface, irrespective of the alloying element. The obtained histograms were fitted by a Gaussian function:

$$
y(x)=\frac{1}{\sigma \sqrt{2 \pi}} e^{-\frac{\left(x-x_{a v}\right)^{2}}{2 \sigma^{2}}},
$$

where $x_{a v}$ is the average value and $\sigma$ is the standard deviation.

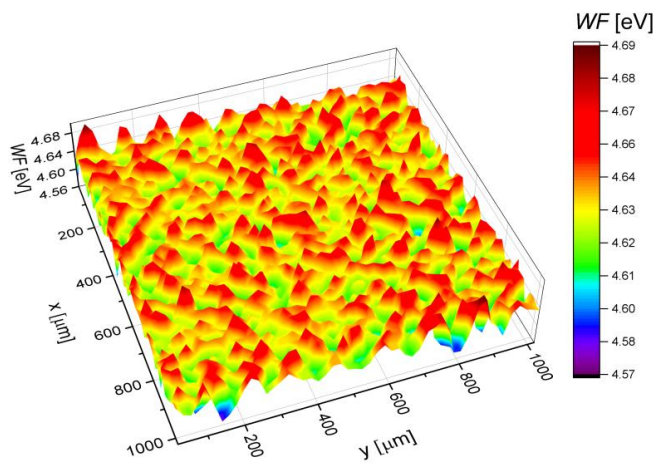

(a)

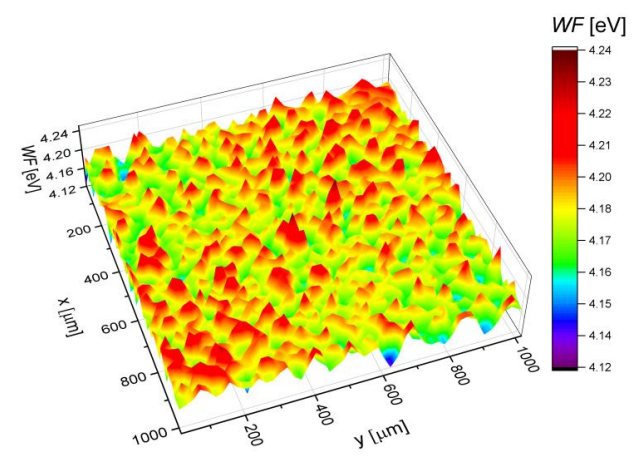

(c)

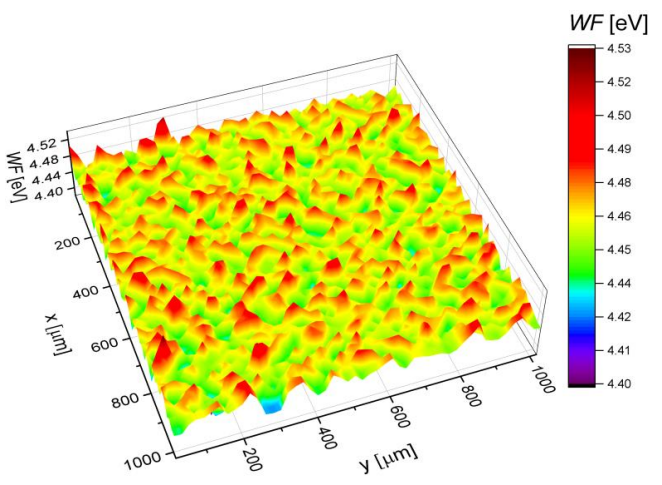

(b)

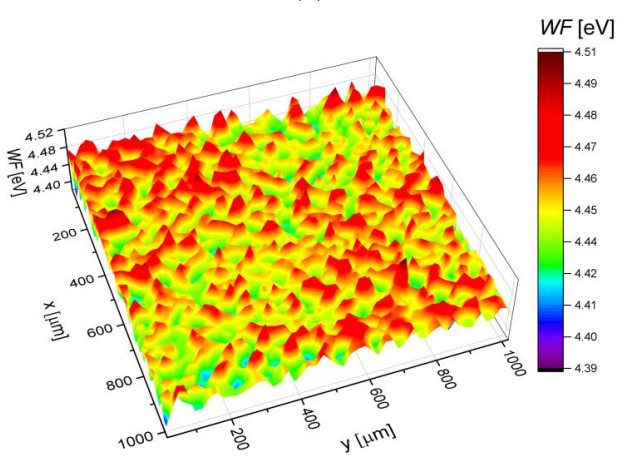

(d)

Figure 3. Work function maps determined for as-deposited electrodes: (a) Pd; (b) Pd-Rh; (c) Pd-Ru; (d) Pd-Pt. 


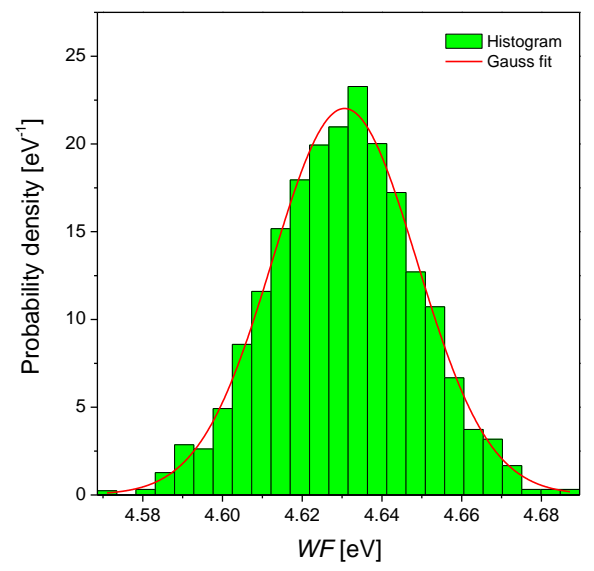

(a)

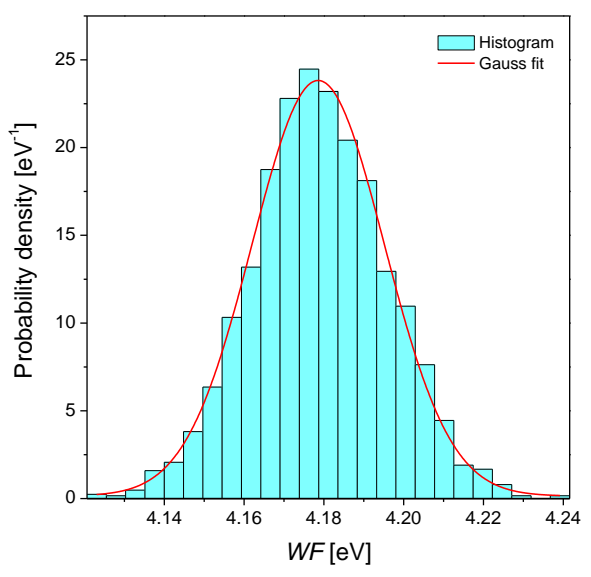

(c)

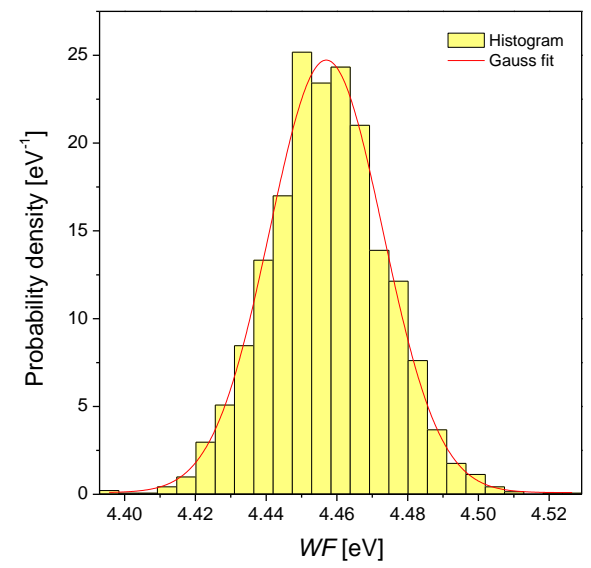

(b)

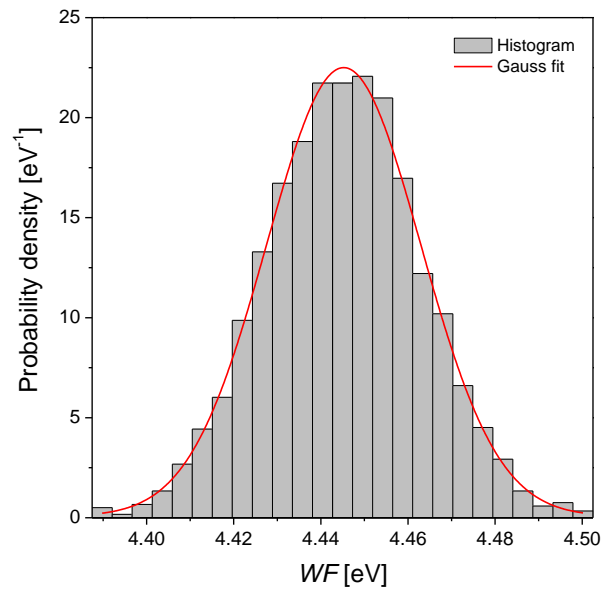

(d)

Figure 4. Distribution histogram of work function corresponding to Figure 3 for as-deposited electrodes: (a) Pd; (b) Pd-Rh; (c) Pd-Ru; (d) Pd-Pt. Continuous red lines represent fits obtained using the Gaussian function.

Table 4 presents the average values of the work function $\left(W F_{a v}\right)$ and standard deviation $(\sigma)$ calculated based on the histograms, the literature values of WF for pure metals and alloys, and the values of the Fermi level energies calculated based on the approach proposed by Hara et al. [42] and values of $E_{F}$ of pure metals taken from the work of Papaconstantopoulos [43].

Table 4. Theoretical values of the Fermi level energy $\left(E_{\mathrm{F}}\right)$ of the electrodeposited Pd and Pd-binary alloys and average work function $\left(W F_{\text {av }}\right)$ and standard deviation $(\sigma)$ calculated using histograms shown in Figure 4a-d $\left(W F_{\text {av }}\right)$ as well as work function taken from the literature for alloys and pure metals $\left(W F_{\text {lit }}\right)$.

\begin{tabular}{|c|c|c|c|c|c|c|}
\hline Alloy Type & $\begin{array}{c}E_{\mathrm{F}} \text { Calculated } \\
{[\mathrm{eV}]^{1}}\end{array}$ & $W F_{\mathrm{av}}[\mathrm{eV}]$ & $\sigma[\mathrm{eV}]$ & $W F_{\text {lit }}[\mathrm{eV}]$ & Metal & $W F_{\text {lit }}[\mathrm{eV}]^{2}$ \\
\hline $\mathrm{Pd}$ & 7.06 & $4.63(1)$ & $18.1(4) \times 10^{-3}$ & & $\mathrm{Pd}$ & 5.12 \\
\hline Pd-Rh & 7.11 & $4.46(1)$ & $16.0(5) \times 10^{-3}$ & $4.76^{3}$ & $\mathrm{Rh}$ & 4.98 \\
\hline Pd-Ru & 7.19 & $4.18(1)$ & $16.5(5) \times 10^{-3}$ & & $\mathrm{Ru}$ & 4.71 \\
\hline $\mathrm{Pd}-\mathrm{Pt}$ & 7.11 & $4.45(1)$ & $17.1(3) \times 10^{-3}$ & & $\mathrm{Pt}$ & 5.65 \\
\hline
\end{tabular}

${ }^{1}[42,43],{ }^{2}[44],{ }^{3}$ for $\mathrm{Pd}_{80} \mathrm{Rh}_{20}[22]$.

The calculated $\mathrm{E}_{F}$ values for Pd and its alloys show that there is no significant difference in the position of the $E_{F}$ for the tested samples. In part, it results from the relatively low amount of the alloying metal $(\mathrm{Rh}, \mathrm{Ru}, \mathrm{Pt})$. However, one can see that the position of $\mathrm{E}_{F}$ is the lowest for Pd and the highest for Pd-Ru alloy, which is in agreement with the 
measured $W F_{a v}$ and electrochemical data. According to Halas and Durakiewicz [44], for pure $\mathrm{Pd}$, the $\mathrm{E}_{\mathrm{F}}$ position, which equals ca. $7.69 \mathrm{eV}$, relates to the $W F$ of ca. $5.12 \mathrm{eV}$. This value is higher than the one obtained from SKP measurements, which is ca. $4.63 \mathrm{eV}$. It is also worth noting that the surface oxides' presence modifies the value of WF for every tested electrode. The above means that the WF theoretical value calculated for unoxidized metal/alloy in every case should be lower than the measured one since it is more difficult to extract an electron from an oxidized surface. Moreover, the XPS analysis of pure Pd and some of its selected binary alloys revealed that the Pd surface is oxidized in ca. $50 \%$. The surfaces of alloy electrodes are oxidized in ca. 15-30\% (depending on the type of alloy and its composition) [36]. However, in most cases, a few different effects have an impact on the $W F$ value. Another parameter that influenced the value of $W F_{a v}$ through the change of the position of $E_{F}$ is connected with the surface roughness of the tested electrodes. As mentioned above, the $\mathrm{E}_{F}$ increase occurs when the surface dipole is modified, which follows in rough surfaces. For the Pd-Ru alloy with the highest $f$, the value of $W F_{a v}$ is the lowest. Onuferko et al. [45] and Losiewicz et al. [22] also relate the decrease of the WF with the increase of the surface roughness. WF values can also be different even for the electrodes of the same compositions but obtained by various methods. In Table 4, there is an example of a $\mathrm{Pd}_{80} \mathrm{Rh}_{20}$ electrode for which the value of $W F_{\mathrm{av}}$ is ca. $4.76 \mathrm{eV}$. This alloy electrode was obtained by arc-melting the $\mathrm{Pd}$ and $\mathrm{Rh}$ followed by annealing in argon in $650{ }^{\circ} \mathrm{C}$. Assuming the WF linear correlation with the composition, it can be calculated that WF of the electrodeposited Pd-Rh electrode, containing 20 at.\% Rh will be ca. $4.52 \mathrm{eV}$. This value is lower than for the arc-melted electrode. This example shows that WF value can also be modified by the preparation method of the electrode. It was found that the spread of the WF distribution around the average (represented by $\sigma$, Table 4) is comparable for investigated Pd-binary alloys. Moreover, standard deviation values indicate that ca. $95 \%$ of all measured WF values on the surface of $\mathrm{Pd}$ and Pd-binary alloys are in range $W F_{a v} \pm 0.03 \mathrm{eV}$; thus, WF varies slightly over the surface for all the investigated materials.

\subsection{Electrochemical Impedance Spectroscopy}

Complex-plane impedance plots, $-Z^{\prime \prime}=f\left(Z^{\prime}\right)$, recorded at the $O C P$ for electrodeposited Pd and binary Pd-based electrodes in $0.5 \mathrm{M} \mathrm{H}_{2} \mathrm{SO}_{4}$ were presented in Figure 5. Two semicircles were visible for all tested electrodes. The diameter of the weakly developed semicircles at the high frequency (HF) range was significantly smaller than the diameter of the semicircles recorded in the low frequency (LF) range.

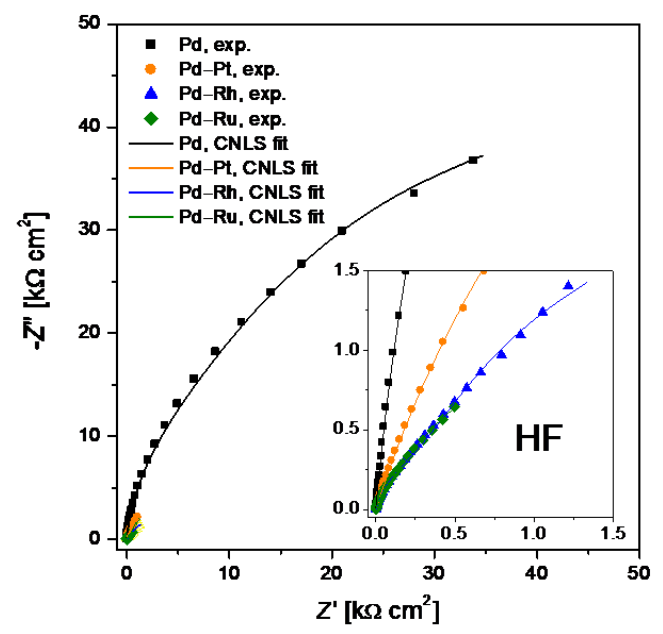

Figure 5. Complex-plane impedance plots obtained for electrodeposited $\mathrm{Pd}, \mathrm{Pd}-\mathrm{Rh}, \mathrm{Pd}-\mathrm{Ru}$, and Pd-Pt electrodes in deaerated $0.5 \mathrm{M} \mathrm{H}_{2} \mathrm{SO}_{4}$ at the open circuit potential. Symbols and continuous lines represent experimental data and fits obtained using the equivalent electrical circuit shown in Figure 6 respectively. 


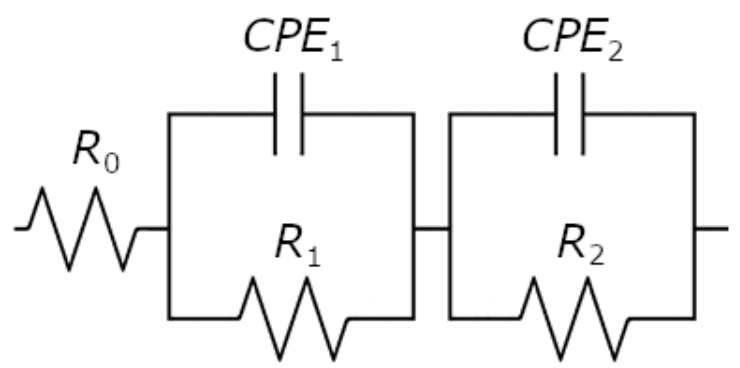

Figure 6. Equivalent electrical circuit model for the corrosion process used for CNLS-fitting.

The corresponding Bode plots in the form of impedance magnitude (log $|Z|)$ and phase angle $(\varphi)$ versus $\log$ frequency $(\log f)$ are shown in Figure $7 \mathrm{a}$ and $\mathrm{b}$, respectively. The experimental values of $|Z|_{f \rightarrow 0}$ and $\varphi$ revealed that the tested electrodes were materials with capacitive behavior and high corrosion resistance. The values of $\log |Z|$ at the lowest frequency studied indicated deterioration of the barrier properties for binary $\mathrm{Pd}$-based alloys compared to the Pd electrode (Figure 7a). Bode impedance plots indicated the occurrence of two time constants in Figure $7 \mathrm{~b}$. A wide plateau in the mid-frequency range for the Pd electrode confirmed its strongest barrier properties among all tested electrodes. The maximum values of $\varphi$ are below $-90^{\circ}$. The phase shift angle varies from 0 to $-90^{\circ}$ indicating capacitive behavior of all investigated electrodes (Figure $7 \mathrm{~b}$ ). Moreover, the plateau, which is observed in the relationship $\varphi$ vs. the $\log f$ performed for Pd indicates that for this electrode the main process taking place at the electrode-electrolyte interface is charging the electrical double layer. Thus, for the Pd electrode, the rate of the charge transfer process through the electrode-electrolyte interface is low, which means good barrier properties of the oxides formed on its surface and, at the same time, high corrosion resistance of this electrode. The impedance modulus determined at $f \rightarrow 0$ is comparable with the polarization resistance of the electrode. On this basis, it can be concluded that the resistance of oxides formed on the surface of the tested electrodes is the highest in the case of the Pd electrode, and thus the Pd electrode shows the best barrier properties. Among Pd alloys, the best barrier properties (the highest $\log |\mathrm{Z}|$ ) is shown by the Pd-Pt electrode.

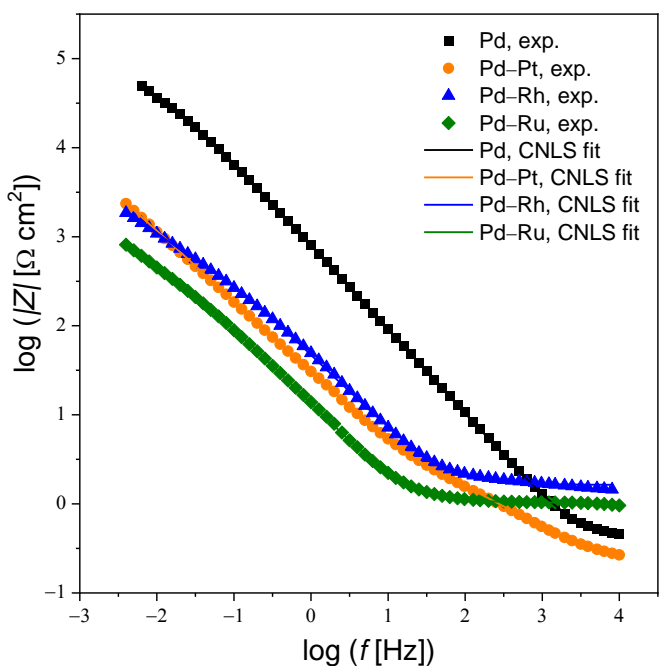

(a)

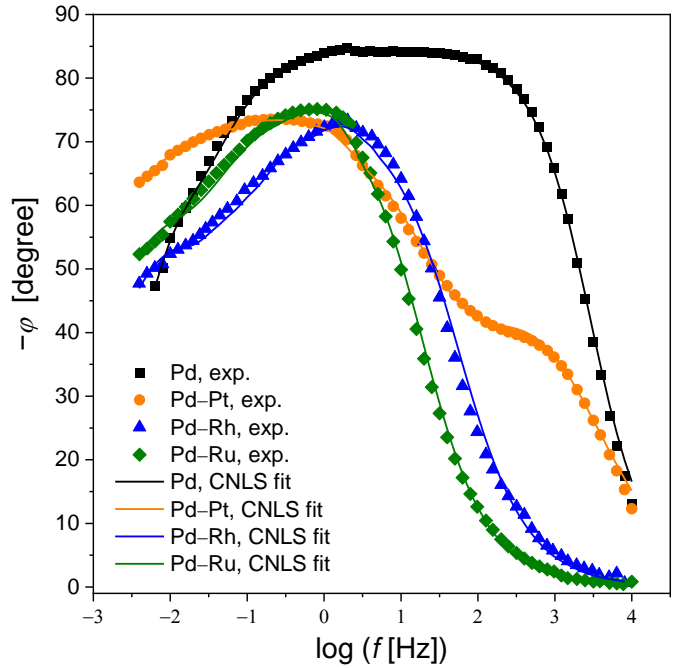

(b)

Figure 7. Bode plots versus $\log$ frequency $(\log f)$ for electrodeposited Pd, Pd-Rh, Pd-Ru and Pd-Pt electrodes in deaerated $0.5 \mathrm{M} \mathrm{H}_{2} \mathrm{SO}_{4}$ at the open circuit potential: (a) Magnitude of impedance (log I Z I); (b) Phase angle $(\varphi)$. Symbols represent experimental data. Continuous lines are fits obtained using the equivalent electrical circuit shown in Figure 6. 
The experimental EIS spectra were fitted using the equivalent electrical circuit shown in Figure 6. It is the so-called two-CPE model with five elements, i.e., $R_{0}, R_{1}, C P E_{1}, R_{2}$, and $C P E_{2}$, where $R$ and $C P E$ denote resistors and constant phase elements, respectively [46]. $C P E$ is an electrical circuit component that models a behavior of a double layer, which is an imperfect capacitor. It is due to the presence of physical, chemical, or geometrical inhomogeneities on the electrode surface [46]. The following equation gives the impedance of the CPE $\left(\hat{Z}_{\mathrm{CPE}}\right)$ :

$$
\hat{Z}_{\mathrm{CPE}}=\frac{1}{T(j \omega)^{\phi}}
$$

where $T$ is the capacitive parameter and $\varphi$ determines the constant phase angle. Note that when $\phi=1$, then $T=C$ and Equation (2) is the same as that for the impedance of a perfect capacitor. The components of the electrical circuit shown in Figure 6 assume a two-layer structure of the film (porous outer layer and tight inner layer) on the electrode surface. In this model, $R_{0}$ represents the solution resistance, $\left(R_{1} C P E_{1}\right)$ and $\left(R_{2} C P E_{2}\right)$ can be associated with outer and inner layers, respectively. The obtained values of the $R_{0}, T_{1}, \phi_{1}, R_{1}, T_{2}, \phi_{2}$, $R_{2}$ parameters are gathered in Table 5 .

Table 5. The value of parameters obtained using the equivalent electrical circuit shown in Figure 6.

\begin{tabular}{|c|c|c|c|c|c|c|c|}
\hline Alloy Type & $\begin{array}{c}R_{0} \\
{\left[\Omega \mathrm{cm}^{2}\right]}\end{array}$ & $\begin{array}{c}T_{1} \\
{\left[\mathrm{~F} \mathrm{~cm}^{-2} \mathrm{~s}^{\phi-1}\right]}\end{array}$ & $\phi_{1}$ & $\begin{array}{c}R_{1} \\
{\left[\Omega \mathrm{cm}^{2}\right]}\end{array}$ & $\begin{array}{c}T_{2} \\
{\left[\mathrm{~F} \mathrm{~cm}^{-2} \mathrm{~s}^{\phi-1}\right]}\end{array}$ & $\phi_{2}$ & $\begin{array}{c}R_{2} \\
{\left[\Omega \mathrm{cm}^{2}\right]}\end{array}$ \\
\hline $\mathrm{Pd}$ & $0.44(1)$ & $5.3(3) \times 10^{-4}$ & $0.94(8)$ & $8.4(7) \times 10^{3}$ & $3.8(9) \times 10^{-4}$ & $0.95(7)$ & $82.9(9) \times 10^{3}$ \\
\hline Pd-Rh & $0.39(1)$ & $91(9) \times 10^{-4}$ & $0.88(6)$ & $225(77)$ & $90(9) \times 10^{-4}$ & $0.81(3)$ & $4.8(7) \times 10^{3}$ \\
\hline $\mathrm{Pd}-\mathrm{Ru}$ & $0.43(1)$ & $284(16) \times 10^{-4}$ & $0.85(5)$ & $167(12)$ & $331(19) \times 10^{-4}$ & $0.90(9)$ & $2.0(7) \times 10^{3}$ \\
\hline $\mathrm{Pd}-\mathrm{Pt}$ & $0.38(1)$ & $76(9) \times 10^{-4}$ & $0.69(2)$ & $124(7)$ & $77.1(4) \times 10^{-4}$ & $0.80(1)$ & $13.2(9) \times 10^{3}$ \\
\hline
\end{tabular}

It was stated that $\phi_{1}$ and $\phi_{2}$ parameters are $<1$, explaining the CPE instead of capacitor in the model. The comparison of $R_{1}$ and $R_{2}$ values indicates that electrical and geometrical properties of the inner layer decide about the corrosion resistance of all investigated electrodes. The highest $R_{2}$ is observed for the Pd electrode. For Pd-binary alloys, $R_{2}$ decreases in the following order: $\mathrm{Pd}-\mathrm{Pt}>\mathrm{Pd}-\mathrm{Rh}>\mathrm{Pd}-\mathrm{Ru}$. Generally, the values of $R_{2}$ indicate that the corrosion resistance of Pd-binary alloys decreases compared to the $\mathrm{Pd}$ electrode. Parameter $T_{2}$ shows that the decrease in Pd-binary alloys' corrosion resistance is associated with an increase in the electrochemically active surface in the following order: Pd-Pt $>\mathrm{Pd}-\mathrm{Rh}>\mathrm{Pd}-\mathrm{Ru}$. The corrosion process of Pd alloys causes cracks at the surface of electrodes (Figure 1) and an increase in their electrochemically active surface, represented by $T_{2}$ parameter. The access of the corrosive environment to the inner layer is then facilitated, which causes its degradation and a decrease in $R_{2}$ resistance. The $R_{2}$ values are comparable to the $R_{\mathrm{p}}$ parameter determined in the potentiodynamic measurements (see Tables 2 and 5). A linear correlation was also found between capacitive parameter $T_{2}$ and surface roughness factor $f$ determined after corrosion (see Tables 3 and 5).

\section{Conclusions}

The electrochemical measurements of corrosion resistance parameters revealed that electrodeposited pure $\mathrm{Pd}$ is the most resistant to corrosion in deaerated $0.5 \mathrm{M} \mathrm{H}_{2} \mathrm{SO}_{4}$. It exhibits the highest value of the corrosion potential and polarization resistance and the lowest value of the corrosion current density. This result has been confirmed by the SKP method, which revealed that WF value is the highest for pure Pd compared to alloy electrodes. Based on EIS measurements, the capacitive behavior and high corrosion resistance of all materials were found. The AC impedance behavior of the tested electrodes may be well described using the electrical equivalent circuit containing two-CPE elements. It was confirmed that alloying Pd with relatively low amount of metals such as $\mathrm{Rh}, \mathrm{Ru}$, and $\mathrm{Pt}$ results in a deterioration of their resistance to corrosion in the following order: $\mathrm{Pd}$ $>\mathrm{Pd}-\mathrm{Pt}>\mathrm{Pd}-\mathrm{Rh}>\mathrm{Pd}-\mathrm{Ru}$. It was found that it is probably mainly due to the significant 
difference in surface roughness factor between pure Pd and its alloys. A huge impact of the surface roughness factor on the poor corrosion resistance of Pd-Ru electrode has been observed.

Author Contributions: Conceptualization, K.H., J.K. and B.Ł.; Methodology, K.H., B.Ł. and J.K.; Investigation, K.H., M.P., J.K. and B.Ł.; formal analysis, K.H., B.Ł. and J.K.; writing-original draft preparation, K.H., J.K., B.Ł., M.P. and A.C.; writing-review and editing, K.H., B.Ł., J.K., M.P. and A.C.; visualization, J.K., K.H. and B.Ł. All authors have read and agreed to the published version of the manuscript.

Funding: This research received no external funding.

Institutional Review Board Statement: Not applicable.

Informed Consent Statement: Not applicable.

Data Availability Statement: Not applicable.

Conflicts of Interest: The authors declare no conflict of interest.

\section{References}

1. Sun, D.; Brantley, W.A.; Frankel, G.S.; Heshmati, R.H.; Johnston, W.M. Potentiodynamic polarization study of the corrosion behavior of palladium-silver dental alloys. J. Prosthet. Dent. 2018, 119, 650-656. [CrossRef]

2. Feng, D.; Taskinen, P. Thermodynamic properties of silver-palladium alloys determined by a solid state electrochemical method. J. Mater. Sci. 2014, 49, 5790-5798. [CrossRef]

3. Picard, C.; Kleppa, O.J.; Boureau, G. High-temperature thermodynamics of the solutions of hydrogen in palladium-silver alloys. J. Chem. Phys. 1979, 70, 2710-2719. [CrossRef]

4. Li, S.; Zuo, Y.; Ju, P. Erosion-corrosion resistance of electroplated Co-Pd film on 316L stainless steel in a hot sulfuric acid slurry environment. Appl. Surf. Sci. 2015, 331, 200-209. [CrossRef]

5. Zhang, H.; Li, Y.; Zuo, Y.; Zhao, X.; Tang, Y. Electrodeposition of multi-layer Pd-Ni coatings on 316L stainless steel and their corrosion resistance in hot sulfuric acid solution. Trans. Nonferr. Met. Soc. China 2017, 27, 1543-1550. [CrossRef]

6. Tang, J.; Zhang, Z.; Wang, Y.; Ju, P.; Tang, Y.; Zuo, Y. Corrosion resistance mechanism of palladium film-plated stainless steel in boiling $\mathrm{H}_{2} \mathrm{SO}_{4}$ solution. Corros. Sci. 2018, 135, 222-232. [CrossRef]

7. Song, J.; Wang, L.; Zibart, A.; Koch, C. Corrosion protection of electrically conductive surfaces. Metals 2012, 2, 450-477. [CrossRef]

8. Huang, Y.H.; Yang, S.P.; Lee, P.T.; Kuo, T.T.; Ho, C.E. Significant improvement of the thermal stability and electrochemical corrosion resistance of the $\mathrm{Au} / \mathrm{Pd}$ surface finish through catalytic modification. Corros. Sci. 2019, 146, 112-120. [CrossRef]

9. Shao, M.; Liu, P.; Zhang, J.; Adzic, R. Origin of enhanced activity in palladium alloy electrocatalysts for oxygen reduction reaction. J. Phys. Chem. B 2007, 111, 6772-6775. [CrossRef] [PubMed]

10. Pötzelberger, I.; Mardare, C.C.; Uiberlacker, L.M.; Hild, S.; Mardare, A.I.; Hassel, A.W. Electrocatalysis on copper-palladium alloys for amperometric formaldehyde sensing. RSC Adv. 2017, 7, 6031-6039. [CrossRef]

11. Gunji, T.; Ochiai, H.; Ohira, T.; Liu, Y.; Nakajima, Y.; Matsumoto, F. Preparation of various Pd-based alloys for electrocatalytic $\mathrm{CO}_{2}$ reduction reaction-selectivity depending on secondary elements. Chem. Mater. 2020, 32, 6855-6863. [CrossRef]

12. Vedyagin, A.A.; Shubin, Y.V.; Kenzhin, R.M.; Plyusnin, P.E.; Stoyanovskii, V.O. The Attractiveness of the Ternary Rh-Pd-Pt Alloys for CO Oxidation Process. Processes 2020, 8, 928. [CrossRef]

13. Vedyagin, A.A.; Plyusnin, P.E.; Rybinskaya, A.A.; Shubin, Y.V.; Mishakov, I.V.; Korenev, S.V. Synthesis and study of Pd-Rh alloy nanoparticles and alumina-supported low-content Pd-Rh catalysts for CO oxidation. Mater. Res. Bull. 2018, 102, 196-202. [CrossRef]

14. Vedyagin, A.A.; Volodin, A.M.; Stoyanovskii, V.O.; Kenzhin, R.M.; Slavinskaya, E.M.; Mishakov, I.V.; Plyusnin, P.E.; Shubin, Y.V. Stabilization of active sites in alloyed Pd-Rh catalysts on $\gamma-\mathrm{Al}_{2} \mathrm{O}_{3}$ support. Catal. Today 2014, 238, 80-86. [CrossRef]

15. Fazle Kibria, A.K.M.; Sakamoto, Y. The effect of alloying of palladium with silver and rhodium on the hydrogen solubility, miscibility gap and hysteresis. Int. J. Hydrogen Energy 2000, 25, 853-859. [CrossRef]

16. Comisso, N.; De Ninno, A.; Del Giudice, E.; Mengoli, G.; Soldan, P. Electrolytic hydriding of $\mathrm{Pd}_{79.5} \mathrm{Rh}_{20.5}$ alloy. Electrochim. Acta 2004, 49, 1379-1388. [CrossRef]

17. Duncan, H.; Lasia, A. Hydrogen adsorption/absorption on Pd/Pt(1 11 1) multilayers. J. Electroanal. Chem. 2008, 621, 62-68. [CrossRef]

18. Martin, M.H.; Lasia, A. Study of the hydrogen absorption in Pd in alkaline solution. Electrochim. Acta 2008, 53, 6317-6322. [CrossRef]

19. Hubkowska, K.; Łukaszewski, M.; Czerwiński, A. Influence of temperature on hydrogen electrosorption into palladium-noble metal alloys. Part 2-Palladium-platinum alloys. Electrochim. Acta 2011, 56, 2344-2350. [CrossRef]

20. Hubkowska, K.; Łukaszewski, M.; Czerwiński, A. Pd-Ru electrodeposits with high hydrogen absorption capacity. Electrochem. Commun. 2012, 20, 175-177. [CrossRef] 
21. Koss, U.; Hubkowska, K.; Łukaszewski, M.; Czerwiński, A. Influence of temperature on hydrogen electrosorption into palladiumnoble metal alloys. Part 3: Palladium-rhodium alloys. Electrochim. Acta 2013, 107, 269-275. [CrossRef]

22. Losiewicz, B.; Kubisztal, J.; Osak, P.; Starczewska, O. Effect of hydrogen electrosorption on mechanical and electronic properties of $\mathrm{Pd}_{80} \mathrm{Rh}_{20}$ alloy. Materials 2020, 13, 162. [CrossRef]

23. Losiewicz, B.; Kubisztal, J. Effect of hydrogen electrosorption on corrosion resistance of $\mathrm{Pd}_{80} \mathrm{Rh}_{20}$ alloy in sulfuric acid: EIS and LEIS study. Int. J. Hydrogen Energy 2018, 43, 20004-20010. [CrossRef]

24. Tremblay, J.; Nguyen, N.L.; Rochefort, D. Hydrogen absorption by a palladium electrode from a protic ionic liquid at temperatures exceeding $100{ }^{\circ} \mathrm{C}$. Electrochem. Commun. 2013, 34, 102-104. [CrossRef]

25. Pająk, M.; Hubkowska, K.; Czerwiński, A. The study of hydrogen sorption in palladium limited volume electrode from DEMATFO ionic liquid. J. Electroanal. Chem. 2018, 825, 73-76. [CrossRef]

26. Pająk, M.; Hubkowska, K.; Czerwiński, A. Hydrogen sorption capacity as a tunable parameter in aprotic ionic liquids. Electrochem. Commun. 2020, 118, 106805. [CrossRef]

27. Lewis, F.A. The Palladium/Hydrogen System; Academic Press: London, UK; New York, NY, USA, 1967. [CrossRef]

28. Burch, R. Theoretical aspects of the absorption of hydrogen by palladium and its alloys. Part 1.-A reassessment and comparison of the various proton models. Trans. Faraday Soc. 1970, 66, 736-748. [CrossRef]

29. Wicke, E.; Frölich, K. Electronic and elastic effect in the phase diagrams of binary Pd alloy hydrides. Z. Pchys. Chem. 1989, 163, 35-40. [CrossRef]

30. Moysan, I.; Paul-Boncour, V.; Thiébaut, S.; Sciora, E.; Fournier, J.M.; Cortes, R.; Bourgeois, S.; Percheron-Guégan, A. Pd-Pt alloys: Correlation between electronic structure and hydrogenation properties. J. Alloys Comp. 2001, 322, 14-20. [CrossRef]

31. Hubkowska, K.; Łukaszewski, M.; Koss, U.; Czerwiński, A. Characterization and electrochemical behavior of Pd-rich Pd-Ru alloys. Electrochim. Acta 2014, 132, 214-222. [CrossRef]

32. Grdeń, M.; Piaścik, A.; Koczorowski, Z.; Czerwiński, A. Hydrogen electrosorption in Pd-Pt alloys. J. Electroanal. Chem. 2002, 532, 35-42. [CrossRef]

33. Manolova, M.; Böck, R.; Scharf, I.; Mehner, T.; Lampke, T. Electrodeposition of Pd alloys from choline chloride/urea deep eutectic solvents. J. Alloys Comp. 2021, 855, 157462. [CrossRef]

34. Vedyagin, A.A.; Shubin, Y.V.; Kenzhin, R.M.; Plyusnin, P.E.; Stoyanovskii, V.O.; Volodin, A.M. Prospect of Using Nanoalloys of Partly Miscible Rhodium and Palladium in Three-Way Catalysis. Top Catal. 2019, 62, 305-314. [CrossRef]

35. Kostin, G.A.; Plyusnin, P.E.; Filatov, E.U.; Kuratieva, N.V.; Vedyagin, A.A.; Kal'nyi, D.B. Double complex salts $\left[\mathrm{PdL}_{4}\right]\left[\mathrm{RuNO}\left(\mathrm{NO}_{2}\right)_{4} \mathrm{OH}\right]$ $\left(\mathrm{L}=\mathrm{NH}_{3}\right.$, Py) synthesis, structure and preparation of bimetallic metastable solid solution $\mathrm{Pd}_{0.5} \mathrm{Ru}_{0.5}$. Polyhedron 2019, 159, 217-225. [CrossRef]

36. Hubkowska, K.; Łukaszewski, M.; Soszko, M.; Koss, U.; Hamankiewicz, B.; Czerwiński, A. Comparative Physicochemical and Electrochemical Characterization of the Structure and Composition of Thin Pd Binary and Ternary Codeposits with Pt, $\mathrm{Ru}$, and Rh. Materials 2018, 11, 798. [CrossRef]

37. Łukaszewski, M.; Czerwiński, A. Anodic oxidation of Pd alloys with Pt and Rh. J. Alloys Comp. 2009, 473, 220-226. [CrossRef]

38. Hubkowska, K. The Electrochemical Properties of Pd-Ru Alloys. Ph.D. Thesis, Faculty of Chemistry, University of Warsaw, Warsaw, Poland, 2016. Available online: https:/ / depotuw.ceon.pl/bitstream/handle/item/1429/Hubkowska-Kosi\%c5\%84ska_ rozprawa\%20doktorska.pdf?sequence=1 (accessed on 28 May 2021).

39. Łukaszewski, M.; Czerwiński, A. Dissolution of noble metals and their alloys studied by electrochemical quartz crystal microbalance. J. Electroanal. Chem. 2006, 589, 38-45. [CrossRef]

40. Woods, R. Electroanalytical Chemistry; Bard, A.J., Ed.; Marcel Dekker: New York, NY, USA, 1976; Volume 9, pp. 1-162.

41. Klein, A.; Körber, C.; Wachau, A.; Säuberlich, F.; Gassenbauer, Y.; Harvey, S.P.; Proffit, D.E.; Mason, T.O. Transparent Conducting Oxides for Photovoltaics: Manipulation of Fermi Level, Work Function and Energy Band Alignment. Materials 2010, 3, $4892-4914$. [CrossRef]

42. Hara, M.; Wan, L.; Matsuyama, M.; Watanabe, K. Alloying effect on heat of hydride and deuteride formation for Pd-based binary alloys. J. Alloys Comp. 2007, 428, 252-255. [CrossRef]

43. Papaconstantopoulos, D.A. Handbook of the Band Structure of Elemental Solids, 2nd ed.; Springer: New York, NY, USA; London, UK, 2015.

44. Halas, S.; Durakiewicz, T. Work functions of elements expressed in terms of the Fermi energy and the density of free electrons. J. Phys. Condens. Matter 1998, 10, 10815-10826. [CrossRef]

45. Onuferko, J.H.; Woodruff, D.P.; Holland, B.W. LEED structure analysis of the Ni\{100\} $(2 \times 2) \mathrm{C}(\mathrm{p} 4 \mathrm{~g})$ structure; A case of adsorbate-induced substrate distortion. Surf. Sci. 1979, 87, 357-374. [CrossRef]

46. Lasia, A. Electrochemical Impedance Spectroscopy and Its Applications; Springer Science \& Business Media: New York, NY, USA, 2014. 